\title{
Response of mussel recruits to pollution from the 'Prestige' oil spill along the Galicia coast. A biochemical approach
}

\author{
U. Labarta ${ }^{1, *}$, M. J. Fernández-Reiriz ${ }^{1}$, J. L. Garrido ${ }^{1}$, J. M. F. Babarro ${ }^{1}$, \\ J. M. Bayona ${ }^{2}$, J. Albaigés ${ }^{2}$ \\ ${ }^{1}$ Instituto de Investigaciones Marinas (CSIC), Eduardo Cabello 6, 36208 Vigo, Spain \\ ${ }^{2}$ Instituto de Investigaciones Químicas y Ambientales, Jordi Girona 18, 08034 Barcelona, Spain
}

\begin{abstract}
Postlarval recruits of mussels Mytilus galloprovincialis were sampled in February 2003 at 7 localities along the Galicia coast (NW Spain) exhibiting different levels of impact from the 'Prestige' oil spill. These localities are important grounds for seed collection used in raft culture. The concentrations of polycyclic aromatic hydrocarbons (PAHs) as well as different biochemical and ecophysiological variables were determined in mussel tissues, as indicators of the toxic impact of the spilled oil. The following parameters were measured: size frequency distributions and size-weight relationships, survival in air, biochemical composition (proteins, carbohydrates, glycogen and lipids), lipid classes (phospholipids, sterol esters and waxes, triacylglycerols, free fatty acids and sterols), and fatty acid composition. The study determined sub-lethal effects in wild mussel seed populations sampled 3 mo after the oil spill. These effects are shown in the form of survival indices and alterations of lipid metabolism, especially in trygliceride and sterol fractions, as well as in saturated/monounsaturated fatty acid ratios. Monitoring these effects in wild mussel recruits is important for analysing growth, production and biochemical reserve cycle throughout the raft cultivation period and evaluating the capacity of the individuals to repair alterations detected in the juvenile stage.
\end{abstract}

KEY WORDS: Mussel · Postlarvae · 'Prestige' · Toxic impact · PAH · Biochemical analysis

\section{INTRODUCTION}

In the days following the 'Prestige' oil spill (November $13,2003,42^{\circ} 12.5^{\prime} \mathrm{N}, 12^{\circ} 3^{\prime} \mathrm{W}$ ), winds and ocean currents pushed the oil onshore. This led to an ecological disaster along the Galicia coast in NW Spain, particularly for sessile bivalves and barnacles living in the rocky intertidal zone. Mussels are excellent indicators of contamination levels in the environment as they are sessile and filter feed from the surrounding water. Although mussels cultivated on the 3300 rafts inside the Galician Rías were not directly affected by the oil from the 'Prestige', on average $7500 \mathrm{t}$ of mussel seed are gathered per year from coastal zones affected by the oil spill, particularly the areas between the south of the Pontevedra Ría and Cape Finisterre (Fig. 1).

The uptake and biomagnification of hydrocarbons by marine bivalves depends on the bioavailability, the duration of exposure, and the physiological conditions of the populations. Biotic and abiotic factors influence the filtration rate of the organisms exposed to the contaminants, and thus the accumulation rate of the compounds (Farrington et al. 1982).

Previous research on the effects of the 'Aegean Sea' oil spill that occurred in the same area in December 1992, showed mussel scope-for-growth (SFG) values in contaminated samples were fifty times lower than unaffected specimens (Larretxea \& Pérez-Camacho 1996). In some cases, the alteration of the energetic balance proved to be lethal. The latter study also reported notable hydrocarbon contents in the bivalve tissues, which affected physiological functioning. The reduction in absorption efficiency, implying a lower assimilation yield of ingested food, was caused by histopathological alterations produced by the hydrocarbons in the cells of the digestive gland (responsible for intracellular digestion). 


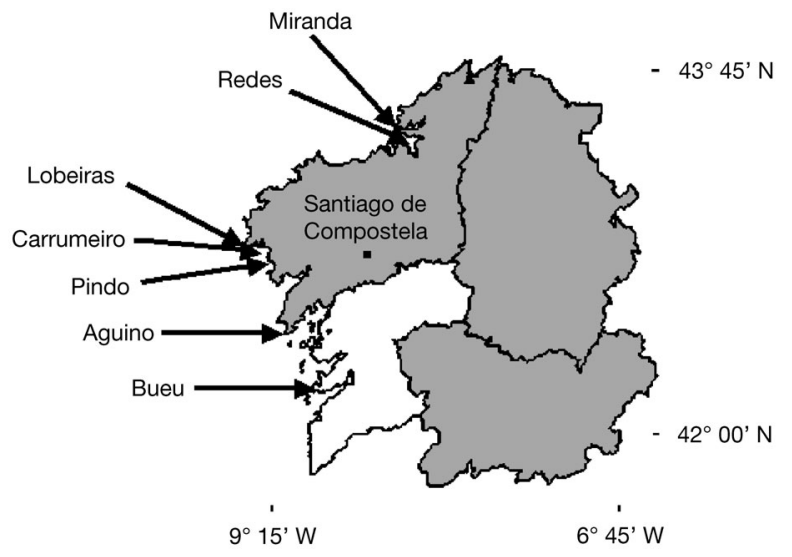

Fig. 1. Locations along a wide geographical area in Galicia, NW Spain, where mussel seed were collected

Studies on the effects of hydrocarbons in bivalves have mainly focussed on general histopathological rather than specific biochemical responses (Capuzzo 1996). Deterioration of lipid metabolism as a response of exposure to lipophilic contaminants has been observed by various authors. Capuzzo et al. (1984) observed a reduction in triacylglycerol synthesis and a decrease in mobilization of fatty acids to the phospholipid pool in larvae of Homarus americannus exposed to petroleum hydrocarbons. Darsie et al. (1976) showed that exposure to lipophilic contaminants can result in deficiency of essential fatty acids, changes in lipid classes and suppression of the transport of triglycerides (Kato et al. 1982). With other lipophilic contaminants such as PCBs, Caldwell et al. (1979) observed alterations in fatty acid profiles as a result of the interaction between mixed function oxygenase and fatty acid desaturase systems.

Our previous studies on mussels under unpolluted environmental conditions established that performance-related growth was associated with differences in seed biochemical reserves (Freites et al. 2002a,b,c, 2003) and physiological behaviour (Babarro et al. 2000a,b,c, 2003). Given the importance of mussel seed supply for sustaining raft cultivation in Galicia (about

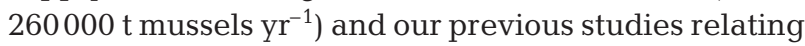
biochemical and physiological characteristics of mussel seed, a study was performed on the biochemical characteristics and the presence of PAHs in mussel tissues, at the seed gathering stage, from different zones of the Galician coast impacted by the 'Prestige' oil spill.

\section{MATERIALS AND METHODS}

Sampling and sample treatment. Postlarval Mytilus galloprovincialis recruits were sampled in 7 localities (characterized by different levels of impact) along the Galician coast in February 2003 (Fig. 1). These locali- ties are important grounds for seed collection for use in raft culture. The mussels were obtained by scraping a given surface of rocky shore in each locality, according to common mussel seed gathering techniques. At each locality and from a sample of $20 \mathrm{~kg}$ of mussels, 3 subsamples were randomly obtained containing 300 individuals each. The following parameters were measured: frequency of size distributions, mean size, shell dry weight, total dry weight, meat dry weight, meat organic weight and condition index (CI).

For the biochemical analyses (proteins, carbohydrates, glycogen, total lipids, lipid classes and fatty acids of total lipids), 3 sub-samples of 10 to 15 individuals were taken at random, thus comprising a total of 30 to 45 individuals from each mussel group. The soft tissues of the individuals of each sub-sample were separated, placed in 3 containers, freeze-dried and stored at $-70^{\circ} \mathrm{C}$. Prior to the development of the different biochemical analyses, the tissues of the mussels were pulverised with a Pulverisette 6 (Fritsch) and homogenised with an ultrasonic Branson Sonifier (250/450 USA). Condition index values were obtained according to the formula: $\mathrm{CI}=\left(\mathrm{DW}_{\text {tissue }} / \mathrm{DW}_{\text {shell }}\right) \times 100$, where $\mathrm{DW}_{\text {tissue }}$ corresponds to dry weight of soft tissues and $\mathrm{DW}_{\text {shell }}$ to dry weight of the shell (Freeman 1974).

Survival profiles. Two replicates of 30 individuals each were exposed to air in a chamber at $18^{\circ} \mathrm{C}$ on filter paper with continuous humidity of approximately $100 \%$. The daily mortality rate was noted. Mussels were considered alive when closed individuals resisted forcible valve separation. Size of individuals for survival profiles was selected from frequency distributions of the whole population and individuals near mean shell length values for each population (see Fig. 2) were exposed in air.

Determination of polycyclic aromatic hydrocarbons (PAHs). Extraction procedure: Collected samples were frozen at $-20^{\circ} \mathrm{C}$ until analysis. Dry weight (DW) was determined in sub-samples by gravimetry following overnight thermal heating at $105^{\circ} \mathrm{C}$.

About 1.5 to $2 \mathrm{~g}$ of the DW sample were transferred into a centrifuge tube and spiked with the following perdeuterated surrogates, naphthalene, anthracene, pyrene and benzo[a]pyrene in methanol and an aqueous $\mathrm{NaOH}$ solution. Samples were heated in a water bath at $40^{\circ} \mathrm{C}$ for $18 \mathrm{~h}$ in the dark and then liquid-liquid extracted with $3 \times 10 \mathrm{ml}$ hexane-dichloromethane (80:20). The recovered extracts were dried and rotary evaporated.

Fractionation: The extracts were fractionated using $6 \mathrm{ml}$ polypropylene cartridges (Interchim) containing $1 \mathrm{~g}$ silica and $0.5 \mathrm{~g}$ cyanopropyl-silica (Alzaga et al. 2004). We collected 2 fractions, (1) aliphatic hydrocarbons eluting with $4 \mathrm{ml}$ of hexane and (2) polycyclic aromatic hydrocarbons with $8 \mathrm{ml}$ of hexane:dichloro- 
methane (1:1). The collected extracts were concentrated under a gentle nitrogen stream.

PAH determination: The PAH fractions were analysed using gas chromatography coupled to mass spectrometry (GC-MS, Thermo-Electron Corporation) in the electron impact (EI) mode at $70 \mathrm{eV}$, with full scan acquisition from 50 to $500 \mathrm{amu}$. Quantification was performed by the internal standard procedure using triphenylamine and recovery correction. Dry weight concentrations were calculated from the wet weight following a correction for water content. Recoveries ranged from 70 to $100 \%$ and blanks were lower than $18 \mathrm{ng} \mathrm{g}^{-1}$. The limit of detection (LOD) in the full scan mode ranged from 0.67 to $7.85 \mathrm{ng} \mathrm{g}^{-1} \mathrm{DW}$.

Biochemical composition. Proteins were determined using the method described by Lowry et al. (1951) after alkaline hydrolysis with $0.5 \mathrm{~N} \mathrm{NaOH}$ at $30^{\circ} \mathrm{C}$. Carbohydrates were quantified as glucose by the phenolsulphuric acid method (Strickland \& Parsons 1968). Glycogen was also quantified as glucose after precipitation with $100 \%$ ethanol. Lipids were extracted according to a modified Bligh \& Dyer (1957) method (Fernández-Reiriz et al. 1989) as follows: lipid material was extracted by means of chloroform-methanol (1:2); after centrifugation, the sediment was extracted again with chloroform-methanol (2:1). To purify the extract both supernatants were washed with a mixture of chloroform, methanol and water (8:4:3). Total lipids were gravimetrically determined through evaporation of the solvent in the purified extract on aluminium sheets at 60 to $80^{\circ} \mathrm{C}$.

Lipid classes. The lipid classes were determined by thin layer chromatography (TLC). The chromatographic plates were developed following the method of Freeman \& West (1966). The plates were developed with a $10 \% \mathrm{CuSO}_{4}$ and $0.85 \% \mathrm{H}_{3} \mathrm{PO}_{4}$ solution heated to $180^{\circ} \mathrm{C}$ (Bitman \& Wood 1982). Standards employed for the quantitative analysis of the sterol and wax esters, sterols, free fatty acids and triglycerides, were cholesterol palmitate, cholesterol, palmitic acid and tripalmitin (Sigma), respectively. The phospholipid standard was obtained from the mussel Mytilus galloprovincialis.

Fatty acids. Fatty acids from total lipids were transesterified to methyl esters with methanolic sulphuric acid, as described by Christie (1989). Subsequent analysis was performed on a gas chromatograph (Perkin-Elmer, 8700) equipped with a fused silica capillary column (Agilent, DB-23) (60 m length, $0.25 \mathrm{~mm}$ i.d.) and a PTV injector (Perkin-Elmer) operated in the solvent elimination mode (Medina et al. 1994). The oven temperature was raised from 170 to $240^{\circ} \mathrm{C}$ at a rate of $2.0^{\circ} \mathrm{C} \mathrm{min}{ }^{-1}$. Nitrogen at $30 \mathrm{psi}$ was used as the carrier gas. Nonadecanoic acid was used as an internal standard.
Fatty acids were identified by co-injection of the samples along with standard mixtures of established composition and by GC-MS of oxazolin derivatives (Garrido \& Medina 1994, 2002).

Statistical analysis. The non-parametric KaplanMeier test was used to estimate log-rank and Wilcoxon values for comparing the survival curves (Kaplan \& Meier 1958). A confidence limit of $95 \%$ was used to test the significance of differences between groups. $\mathrm{LT}_{50}$ values (median survival times) were established using the trimmed Spearman-Karber method $(\alpha=$ $10 \%)$ (Hamilton et al. 1997).

Differences among locations in concentrations of biochemical components and lipid classes were carried out by an ANOVA with a significance level of $\mathrm{p}<0.05$. Percent composition data were transformed by angular transformation (arcsine $\sqrt{\%}$ ) prior to analyses, to ensure normality. The homogeneity of variances was checked by means of the Bartlett test.

Location similarities based in PAH contents was studied with hierarchical cluster analysis using Average Linkage (between groups) method and squared euclidean distance for computing proximity matrix. The data were previously standardized (mean 0 and typical deviation 1).

\section{RESULTS}

Values of mean shell length (SL, mm), total dry weight (total DW, g) and condition index (CI) values are represented in Fig. 2. Mussels from Bueu showed the lowest mean SL values $(11.9 \mathrm{~mm})$ whereas the highest were observed for mussels from Redes (19.8 mm). SL varied from 15.5 to $16.0 \mathrm{~mm}$ for Pindo, Carrumeiro and Miranda mussels and from 17.5-17.7 mm for Lobeiras and Aguiño mussels. The highest CI values were found in mussels from Aguiño (18.6), Lobeiras (17.2) and Pindo (14.6), whereas Redes and Carrumeiro mussels showed similar values (11.8), significantly lower than those of the former populations Aguiño-Lobeiras-Pindo $(p<0.05)$. Bueu (8.8) and Miranda (7.1) populations had the lowest CI ( $p>$ 0.05 between them), which were significantly lower than populations from Redes-Carrumeiro ( $p<0.01$ ) and Aguiño-Lobeiras-Pindo ( $p<0.001)$ (Fig. 2).

\section{Survival profiles}

Survival curves for the mussels are presented in Fig. 3. Two clear subgroups can be observed according to $\mathrm{LT}_{50}$ values. The lowest survival profiles corresponded to individuals from Carrumeiro (5.4 d), Aguiño (5.6 d) and Lobeiras (6.2 d) with no differences between 

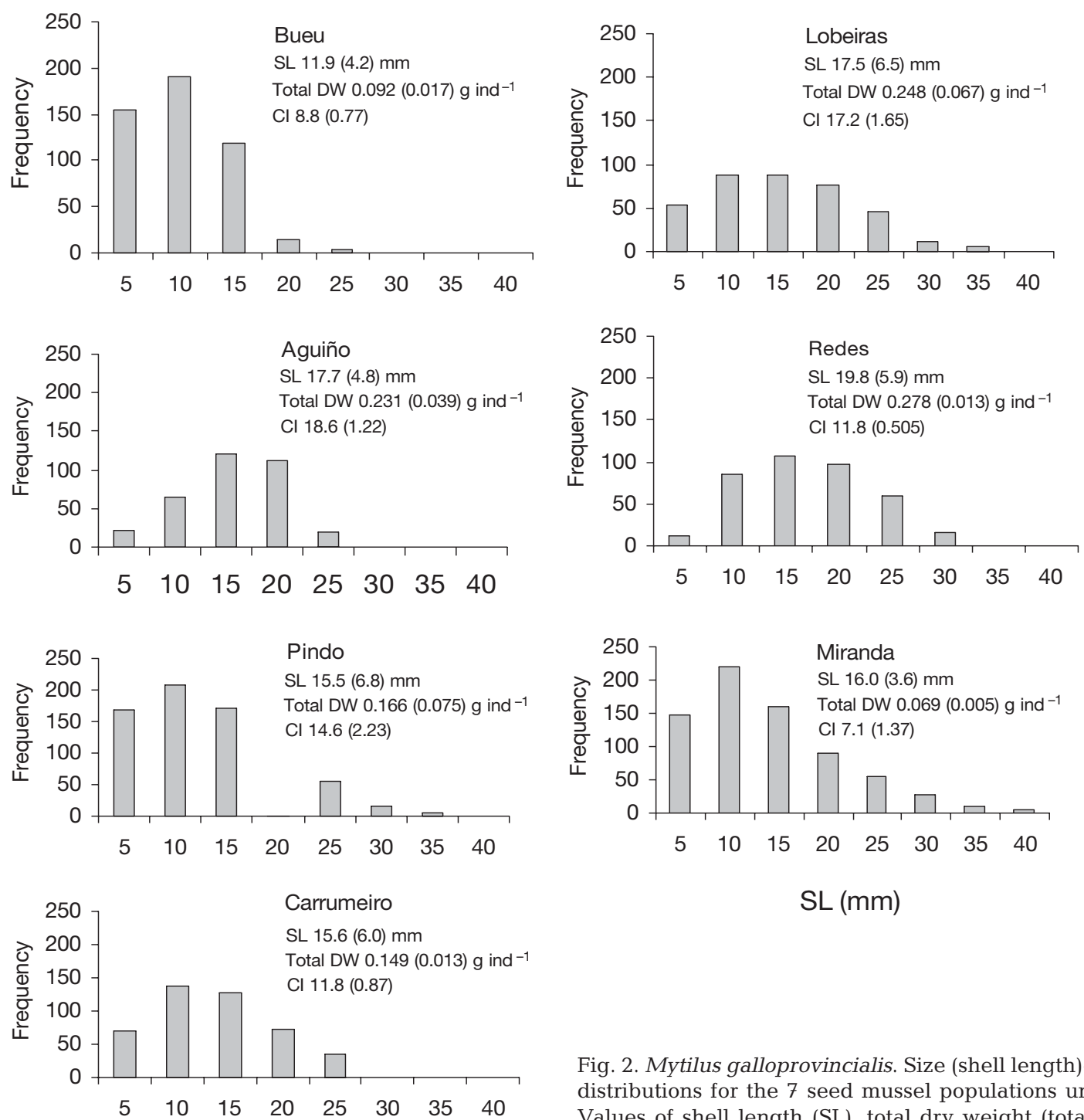

$\mathrm{SL}(\mathrm{mm})$

Fig. 2. Mytilus galloprovincialis. Size (shell length)-frequency distributions for the 7 seed mussel populations under study. Values of shell length (SL), total dry weight (total DW) and condition index (CI) are included with standard deviations in brackets

them ( $p$ > 0.05). Mussels from Pindo presented a $\mathrm{LT}_{50}$ value of $7.14 \mathrm{~d}$, significantly higher than the populations above $(\mathrm{p}<0.01)$ but also significantly lower $(p<0.01)$ than the highest survival values observed for Miranda (8.4 d), Bueu (8.4 d) and Redes (9.4 d).

\section{PAH contents}

The concentrations of total PAHs as well as the relative distribution of the major components in mussel seed from different locations, 3 mo after the 'Prestige' accident, is presented in Fig. 4.

The results of a hierarchical cluster analysis of all these data, shown in Fig. 5, exhibit 3 groupings of the seed locations in agreement with the PAH contents.

Accordingly, a first group comprises seeds from Bueu, Carrumeiro and Redes. Bueu and Redes correspond to the geographical areas farthest from the highest impact of the spill. Carrumeiro, although situated in the centre of the spill zone (Corcubión Bay), is close to the mouth of the Xallas River and the freshwater component in this zone is substantially higher. Another group encompasses Aguiño, Pindo and Lobeiras, which are highly impacted areas on the coastal strip. Finally Miranda, situated in the mouth of the Ferrol Ría in the Artabro Gulf is closer to the first group than to the impacted areas.

For comparison purposes, the PAH composition of the 'Prestige' fuel oil is also included (see http:// csicprestige.iim.csic.es/informes/info01.pdf). Although all samples contain the whole set of 2 to 6 ring PAHs, 


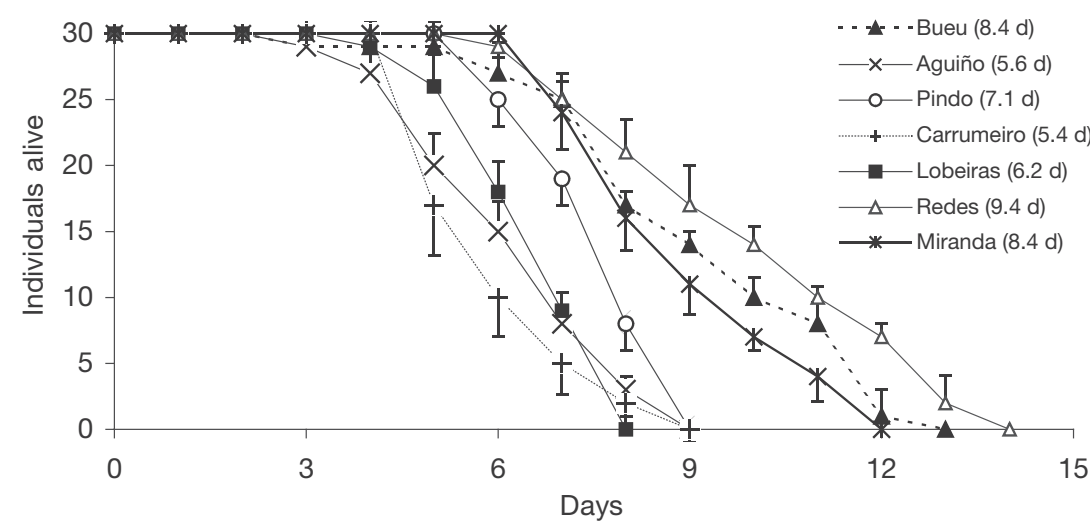

Fig. 3. Mytilus galloprovincialis. Survival profiles of mussel populations under air exposure and constant humidity at $18^{\circ} \mathrm{C}$. Profiles show combination of 2 replicates with a total number of 30 mussels each. Median survival times are shown in parentheses

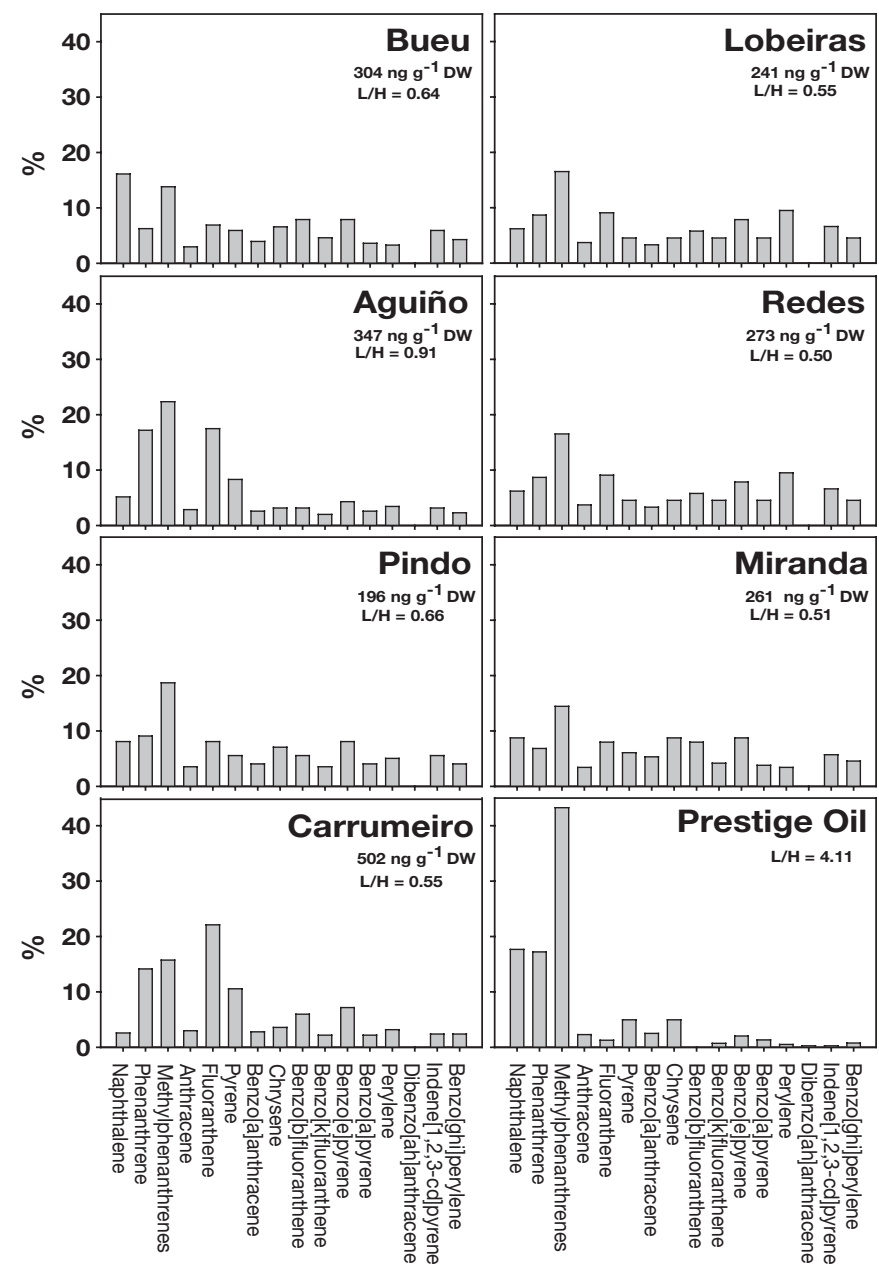

Fig. 4. Mytilus galloprovincialis. Variation of polycyclic aromatic hydrocarbon (PAH) concentrations and relative distribution of the major components in mussel seed from the 7 locations under study and from the oil from the 'Prestige' spill. $\mathrm{L} / \mathrm{H}$ corresponded to the ratio $\sum(2-3$ ring $\mathrm{PAHs}) / \sum(4-6$ ring PAHs) the relative proportion of $2-3$ and 4-6 ring PAHs varies among them, the former being predominant in the oil and in the samples collected between Aguiño and Lobeiras, and the latter in the mussels from Miranda station, close to the industrial area of A Coruña-El Ferrol.

The levels found are difficult to assess because normally data reported in the literature refer to adult species, which probably have a higher filtration and accumulation capacity. Wild mussels collected after the spill in the region were in the range of 1 to $8 \mathrm{ng} \mathrm{g}^{-1} \mathrm{DW}$ (see www.ieo.es/prestige/resultados.htm). The background values found after the 'Aegean Sea' oil spill, in 1992, were in the range of 40 to $200 \mathrm{ng} \mathrm{g}^{-1}$ DW (Porte et al. 2000).

\section{Biochemical composition}

Mytilus galloprovincialis showed no significant differences among different size classes for any of the biochemical compounds studied (1-way ANOVA, p > 0.05).

Proteins were the main component in all mussel seeds and comprised more than $50 \%$ of total organic material. The proportion of protein in seed from Bueu, Carrumeiro and Redes was the highest (about 79\%, $\mathrm{p}<0.05)$ compared with other areas: Miranda and Pindo (about $73 \%$ ) and seeds from Aguiño and Lobeiras (60.6 and 67.8\%, respectively) (Table 1).

The greatest proportions of carbohydrates were found in seeds from Aguiño and Lobeiras (19.6\% and $13.8 \%$, respectively). No significant differences were observed between seeds from Miranda and Pindo

Rescaled Distance Cluster Combine

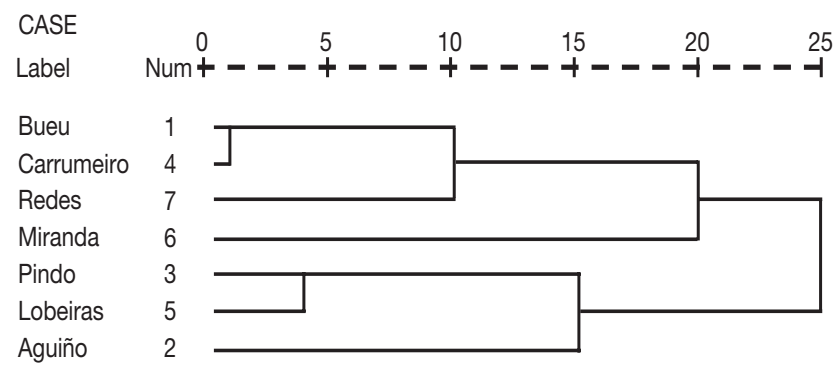

Fig. 5. Mytilus galloprovincialis. Hierarchical cluster analysis using average linkage (between groups) method and squared euclidean distance for concentrations of PAH compounds for the mussel populations under study 
Table 1. Mytilus galloprovincialis. Biochemical composition of seed mussels from 7 localities along the coast of Galicia (NW Spain). Data (mean $\pm \mathrm{SD}$ ) are percentage of total organic matter (OM). Data are standardized to OM estimated by \% ash-free dry weight, with the exception of glycogen. Size classes (shell height in mm): $\mathrm{A}=22.5-27.5 ; \mathrm{B}=17.5-22.5 ; \mathrm{C}=$ $12.5-17.5 ; \mathrm{D}=7.5-12.5 ; \mathrm{E}=2.5-7.5$

\begin{tabular}{|lrrrc|}
\hline Size class & Protein & Carbohydrate & Glycogen & Lipid \\
\hline Bueu & & & & \\
B & $78.7 \pm 0.3$ & $7.2 \pm 0.4$ & $2.0 \pm 0.0$ & $14.1 \pm 0.2$ \\
C & $77.4 \pm 1.1$ & $7.9 \pm 1.2$ & $1.9 \pm 0.1$ & $14.6 \pm 0.1$ \\
D & $80.4 \pm 0.4$ & $6.2 \pm 0.1$ & $1.9 \pm 0.1$ & $13.4 \pm 0.3$ \\
Mean & $78.6 \pm 1.5$ & $7.1 \pm 1.0$ & $1.9 \pm 0.1$ & $14.0 \pm 0.6$ \\
Aguiño & & & & \\
A & $60.2 \pm 1.8$ & $20.2 \pm 1.2$ & $4.5 \pm 0.5$ & $19.6 \pm 0.6$ \\
B & $59.4 \pm 0.4$ & $20.4 \pm 0.8$ & $4.5 \pm 0.2$ & $20.2 \pm 1.2$ \\
C & $62.1 \pm 1.3$ & $18.1 \pm 0.9$ & $3.6 \pm 0.3$ & $19.7 \pm 0.4$ \\
Mean & $60.6 \pm 1.6$ & $19.6 \pm 1.4$ & $4.2 \pm 0.5$ & $19.8 \pm 0.7$ \\
Pindo & & & & \\
B & $73.0 \pm 1.2$ & $9.5 \pm 0.7$ & $2.0 \pm 0.0$ & $17.6 \pm 0.3$ \\
C & $72.6 \pm 0.5$ & $10.2 \pm 0.6$ & $1.8 \pm 0.1$ & $17.1 \pm 0.1$ \\
D & $71.6 \pm 0.8$ & $11.4 \pm 0.8$ & $2.6 \pm 0.4$ & $16.9 \pm 1.6$ \\
Mean & $72.4 \pm 0.9$ & $10.4 \pm 2.1$ & $2.1 \pm 0.4$ & $17.2 \pm 0.8$ \\
Carrumeiro & & & & \\
B & $78.4 \pm 0.6$ & $7.0 \pm 0.2$ & $2.3 \pm 0.1$ & $14.3 \pm 0.4$ \\
C & $77.6 \pm 0.1$ & $7.6 \pm 0.3$ & $1.9 \pm 0.1$ & $13.7 \pm 0.4$ \\
D & $78.8 \pm 0.5$ & $8.0 \pm 0.4$ & $2.3 \pm 0.1$ & $13.8 \pm 0.9$ \\
Mean & $78.3 \pm 0.6$ & $7.6 \pm 0.5$ & $2.2 \pm 0.2$ & $13.9 \pm 0.6$ \\
Lobeiras & & & & \\
A & $69.1 \pm 1.3$ & $13.5 \pm 0.4$ & $3.0 \pm 0.2$ & $17.4 \pm 1.7$ \\
B & $66.3 \pm 1.4$ & $14.3 \pm 0.7$ & $3.0 \pm 0.2$ & $19.4 \pm 0.7$ \\
C & $68.0 \pm 1.0$ & $13.5 \pm 0.8$ & $2.8 \pm 0.5$ & $18.5 \pm 0.2$ \\
Mean & $67.8 \pm 1.6$ & $13.8 \pm 0.6$ & $2.9 \pm 0.3$ & $18.4 \pm 1.2$ \\
Miranda & & & & \\
C & $73.9 \pm 1.1$ & $9.1 \pm 0.7$ & $2.4 \pm 0.0$ & $17.0 \pm 0.4$ \\
D & $72.5 \pm 0.3$ & $8.6 \pm 0.3$ & $2.4 \pm 0.0$ & $18.9 \pm 0.6$ \\
E & $74.5 \pm 0.6$ & $9.1 \pm 1.1$ & $2.5 \pm 0.1$ & $16.4 \pm 0.5$ \\
Mean & $73.7 \pm 1.1$ & $8.9 \pm 0.6$ & $2.4 \pm 0.1$ & $17.4 \pm 1.2$ \\
Redes & & & & \\
A & $79.0 \pm 0.5$ & $7.1 \pm 0.3$ & $2.6 \pm 0.1$ & $13.9 \pm 0.2$ \\
B & $78.3 \pm 0.6$ & $7.8 \pm 0.0$ & $2.0 \pm 0.0$ & $14.0 \pm 0.7$ \\
C & $80.7 \pm 0.6$ & $6.6 \pm 0.2$ & $1.9 \pm 0.0$ & $12.7 \pm 0.5$ \\
Mean & $79.3 \pm 1.1$ & $7.2 \pm 0.5$ & $2.2 \pm 0.3$ & $13.5 \pm 0.8$ \\
\hline
\end{tabular}

(from 8.9 to $10.4 \%$ ). The lowest carbohydrate contents were found in the seeds from Bueu, Carrumeiro and Redes (about $7.1 \%$ ) (Table 1).

With regard to glycogen content, the proportion observed in the seeds from the different origins presented trends similar to those of total carbohydrates. Accordingly, the greatest percentages were observed in the seeds from Aguiño and Lobeiras (4.2 and 2.9\% OM, respectively). The proportions observed in seeds from Miranda, Pindo, Redes and Carrumeiro were similar, and varied from 2.1 to $2.4 \%$. The percentage of glycogen in the seed from Bueu represented the smallest values $(1.9 \%)$ (Table 1$)$.

The proportion of total lipids in seed from Aguiño, Pindo, Lobeiras and Miranda were significantly higher (from 17.2 to $19.8 \%$ ) in comparison with seeds from Bueu, Carrumeiro and Redes (about 14\%) (Table 1).

\section{Lipid classes}

Mytilus galloprovincialis showed no significant differences among different size classes for any of the lipid classes studied (1-way ANOVA, p > 0.05).

Phospholipids were the main lipids present in all seeds except those from Aguiño. The proportion of phospholipids in seeds from Bueu, Redes, Miranda and Carrumeiro were higher ( $p<0.05$, from 75.2 to $68.6 \%$ ) in comparison with seeds from Pindo, Lobeiras and Aguiño (53.8 to $40.3 \%$ ) (see Table 2 for significant differences).

The highest proportions of triglycerides $(p<0.05)$ were found in seeds from Aguiño, Lobeiras and Pindo with significant differences observed between them $(44.5,35.5$ and $26.3 \%$ respectively). Significantly lower proportions $(\mathrm{p}<0.05)$ were found in the seed from Carrumeiro and Miranda (12.4 and 6.2\%, respectively). Triglycerides were not detected in seeds from Bueu and Redes (see Table 2 for significant differences).

The highest proportions ( $p<0.05)$ of sterols were found in seeds from Bueu and Redes (about 13.0\%).

Table 2. Mytilus galloprovincialis. Lipid content of seed. The values are means \pm SD for the 3 size classes. Means within the same columns with different superscript letters are significantly different $(p<0.05)$

\begin{tabular}{|c|c|c|c|c|c|}
\hline & $\begin{array}{c}\text { Phospholipids } \\
(\%)\end{array}$ & $\begin{array}{c}\text { Sterol ester+waxes } \\
(\%)\end{array}$ & $\begin{array}{c}\text { Triacylglycerols } \\
(\%)\end{array}$ & $\begin{array}{c}\text { Free fatty acids } \\
(\%)\end{array}$ & $\begin{array}{l}\text { Sterols } \\
(\%)\end{array}$ \\
\hline Bueu & $75.24 \pm 1.59^{a}$ & $0.00 \pm 0.00$ & $0.00 \pm 0.00$ & $11.78 \pm 1.29^{\mathrm{a}}$ & $12.98 \pm 0.35^{\circ}$ \\
\hline Aguiño & $40.33 \pm 3.12^{\mathrm{b}}$ & $0.00 \pm 0.00$ & $44.55 \pm 3.78^{\mathrm{a}}$ & $10.49 \pm 1.26^{\mathrm{a}}$ & $4.63 \pm 0.57^{\mathrm{b}}$ \\
\hline Pindo & $55.73 \pm 4.02^{\mathrm{c}}$ & $0.00 \pm 0.00$ & $26.26 \pm 4.18^{b}$ & $7.91 \pm 0.89^{\mathrm{a}}$ & $10.10 \pm 0.92$ \\
\hline Carrumeiro & $68.61 \pm 2.07^{a}$ & $0.00 \pm 0.00$ & $12.40 \pm 1.66^{\mathrm{c}}$ & $8.41 \pm 0.77^{a}$ & $10.57 \pm 1.45$ \\
\hline Lobeiras & $50.79 \pm 3.82^{\mathrm{d}}$ & $0.00 \pm 0.00$ & $35.48 \pm 3.99^{\mathrm{d}}$ & $8.34 \pm 1.80^{\mathrm{a}}$ & $5.39 \pm 0.59^{b}$ \\
\hline Miranda & $71.89 \pm 7.67^{\mathrm{a}}$ & $0.00 \pm 0.00$ & $6.16 \pm 2.47^{\mathrm{e}}$ & $13.94 \pm 5.07^{\mathrm{a}}$ & $11.09 \pm 1.02$ \\
\hline Redes & $74.94 \pm 1.89^{a}$ & $0.00 \pm 0.00$ & $0.00 \pm 0.00$ & $12.10 \pm 0.91^{\mathrm{a}}$ & $12.97 \pm 1.04^{\mathrm{a}}$ \\
\hline
\end{tabular}


The lowest $(p<0.05)$ proportions were found in seeds from Aguiño and Lobeiras (about 4.8\%). Mussel seed from Pindo, Carrumeiro and Miranda showed values of about $10.5 \%$ (see Table 2 for significant differences).

Proportions of free fatty acids in seeds from all origins were similar $(\sim 10 \%)$ (see Table 2 for significant differences).
Fatty acids

The analysis of fatty acids revealed different compositions depending on the sampling zone (Table 3). According to this, the samples can be classified into 2 large groups: the first encompassing samples from Aguiño, Lobeiras and Pindo, and generally characterized by abnormally high levels of palmitoleic acid (16:1

Table 3. Mytilus galloprovincialis. Fatty acid profiles of seed mussels. Values are expressed as percentage of total lipids and represent the mean of 2 replicates

\begin{tabular}{|c|c|c|c|c|c|c|c|}
\hline \multirow[t]{2}{*}{ Fatty acid } & \multicolumn{7}{|c|}{ Sampling locations } \\
\hline & Aguiño & Bueu & Carrumeiro & Lobeiras & Miranda & Pindo & Redes \\
\hline $14: 0$ & 2.9 & 1.3 & 2.8 & 4.2 & 1.7 & 2.7 & 1.2 \\
\hline $15: 0$ & 0.5 & 0.8 & 0.8 & 0.5 & 0.7 & 0.8 & 1.0 \\
\hline $\mathrm{DMA}^{\mathrm{a}} 16: 0$ & - & 0.6 & 0.4 & - & 0.1 & 0.2 & 0.2 \\
\hline $16: 0$ & 15.6 & 16.8 & 16.9 & 17.6 & 17.7 & 19.6 & 16.8 \\
\hline $16: 1 \mathrm{n} 7$ & 13.4 & 2.0 & 3.4 & 7.7 & 3.4 & 6.7 & 1.6 \\
\hline $\mathrm{DMA}^{\mathrm{a}} 17: 0$ & 0.7 & 0.2 & - & - & 0.3 & 0.3 & 0.5 \\
\hline $17: 0$ & 2.5 & 1.4 & 1.5 & 1.3 & 1.1 & 1.4 & 1.5 \\
\hline $17: 1 \mathrm{n} 9$ & 0.8 & - & - & 0.2 & 0.1 & 0.2 & - \\
\hline $\mathrm{DMA}^{\mathrm{a}}$ 18:0 & 1.0 & 3.4 & 3.4 & 1.7 & 3.9 & 3.1 & 4.4 \\
\hline $18: 0$ & 2.8 & 5.4 & 4.7 & 3.8 & 5.0 & 5.1 & 5.8 \\
\hline $18: 1 \mathrm{n} 9$ & 1.1 & 1.5 & 1.5 & 2.2 & 1.9 & 1.5 & 1.3 \\
\hline $18: 1 \mathrm{n} 7$ & 2.0 & 1.6 & 1.7 & 2.2 & 2.0 & 2.3 & 1.5 \\
\hline $18: 2 \mathrm{n} 6$ & 1.0 & 1.2 & 1.2 & 2.4 & 1.6 & 1.1 & 1.0 \\
\hline $18: 3 \mathrm{n} 6$ & 0.9 & - & 0.2 & 0.4 & 0.1 & 0.4 & 0.1 \\
\hline $18: 3 \mathrm{n} 4$ & 0.3 & 0.6 & 0.5 & 0.3 & 0.4 & 0.3 & 0.6 \\
\hline $18: 3 \mathrm{n} 3$ & 0.6 & 0.7 & 1.6 & 1.2 & 1.3 & 1.5 & 0.6 \\
\hline $18: 4 \mathrm{n} 3$ & 4.6 & 2.0 & 4.0 & 2.9 & 2.2 & 3.7 & 1.5 \\
\hline $\mathrm{DMA}^{\mathrm{a}} 20: 1$ & 1.4 & - & 0.1 & 0.4 & - & 0.3 & - \\
\hline $20: 0$ & 0.6 & - & - & - & - & 0.0 & - \\
\hline $20: 1 \mathrm{n} 11$ & 0.8 & 1.8 & 1.5 & 1.0 & 1.4 & 1.1 & 1.9 \\
\hline $20: 1 n 9$ & 1.5 & 3.7 & 2.9 & 2.3 & 3.0 & 2.5 & 4.2 \\
\hline $20: 1 \mathrm{n} 7$ & 1.2 & 1.0 & 1.0 & 1.0 & 0.8 & 1.1 & 0.8 \\
\hline $20: 2 \operatorname{NMID}^{\mathrm{b}}(\Delta 5.11)$ & 1.3 & 5.6 & 3.8 & 2.0 & 3.6 & 2.6 & 6.4 \\
\hline $20: 2 \operatorname{NMID}^{\mathrm{b}}(\Delta 5.13)$ & 0.4 & 1.1 & 1.1 & 0.6 & 0.9 & 0.9 & 1.4 \\
\hline $20: 2 n 6$ & 0.4 & 0.5 & 0.6 & 0.6 & 0.5 & 0.4 & 0.5 \\
\hline 20:3 $\operatorname{NMIT}^{\mathrm{c}}(\Delta 5.11 .14)$ & 0.3 & 0.6 & 0.5 & 0.4 & 0.4 & 0.4 & 0.7 \\
\hline $20: 3 n 6$ & 0.1 & - & 0.0 & 0.1 & 0.1 & 0.1 & 0.0 \\
\hline $20: 4 n 6$ & 1.5 & 6.0 & 3.3 & 1.7 & 2.7 & 2.0 & 4.1 \\
\hline $20: 4 n 3$ & 0.6 & - & 0.4 & 0.4 & 0.2 & 0.4 & - \\
\hline $20: 5 n 3$ & 27.3 & 10.9 & 13.7 & 24.8 & 14.5 & 16.6 & 10.0 \\
\hline $22: 2 \operatorname{NMID}^{\mathrm{b}}(\Delta 7.13)$ & 2.3 & 5.8 & 4.4 & 2.6 & 4.0 & 3.7 & 5.7 \\
\hline $22: 3 \operatorname{NMIT}^{\mathrm{c}}(\Delta 7.13 .16)$ & 1.5 & 2.1 & 1.7 & 1.3 & 1.5 & 1.3 & 2.4 \\
\hline $22: 4 \mathrm{n} 6$ & - & 0.8 & 0.6 & 0.3 & 0.7 & 0.4 & 0.9 \\
\hline $22: 5 n 3$ & 0.7 & 1.1 & 1.0 & 1.0 & 6.1 & 1.0 & 1.2 \\
\hline $22: 6 n 3$ & 7.5 & 19.5 & 18.6 & 10.9 & 16.0 & 14.0 & 20.1 \\
\hline$\sum$ Saturated & 24.9 & 25.8 & 26.7 & 27.5 & 26.3 & 29.6 & 26.4 \\
\hline$\sum$ Monounsaturated & 20.9 & 11.6 & 12.1 & 16.7 & 12.6 & 15.6 & 11.3 \\
\hline$\sum$ Polyunsaturated & 50.1 & 56.0 & 54.9 & 52.1 & 55.1 & 49.5 & 54.7 \\
\hline$\sum \mathrm{DMAS}^{\mathrm{a}}$ & 3.0 & 4.1 & 4.0 & 2.1 & 4.3 & 3.9 & 5.2 \\
\hline$\sum n-3$ & 41.9 & 34.5 & 39.4 & 41.2 & 40.5 & 37.6 & 34.0 \\
\hline$\sum \mathrm{n}-6$ & 3.9 & 8.5 & 5.8 & 5.4 & 5.7 & 4.5 & 6.7 \\
\hline$\sum n-7$ & 16.6 & 4.5 & 6.1 & 11.0 & 6.3 & 10.2 & 3.9 \\
\hline$\sum \mathrm{n}-9$ & 3.4 & 5.2 & 4.5 & 4.7 & 5.0 & 4.2 & 5.5 \\
\hline$\sum \mathrm{n}-11$ & 0.9 & 1.8 & 1.5 & 1.0 & 1.4 & 1.1 & 1.9 \\
\hline$\sum$ PUFA n-3 & 41.3 & 33.7 & 37.7 & 40.0 & 39.2 & 36.1 & 33.3 \\
\hline n-3/n6 & 10.7 & 4.1 & 6.8 & 7.6 & 7.2 & 8.4 & 5.1 \\
\hline$\sum$ NMI & 5.8 & 15.2 & 11.5 & 6.9 & 10.5 & 8.8 & 16.5 \\
\hline$\sum$ NMID & 4.0 & 12.5 & 9.2 & 5.2 & 8.5 & 7.1 & 13.4 \\
\hline$\sum$ NMIT & 1.8 & 2.7 & 2.3 & 1.7 & 2.0 & 1.7 & 3.1 \\
\hline
\end{tabular}


n7) and unusually low contents of docosahexaenoic acid (22:6n3), and the second, including the rest of the samples and showing fatty acid compositions similar to those already described for mussel seed originating from unpolluted intertidal environments (Freites et al. 2002b).

\section{DISCUSSION}

\section{Survival profiles}

Survival in air appears to be an extraordinarily significant parameter for monitoring the effect of longterm exposure to crude oil (Thomas et al. 1999). Contaminant exposure may alter the ability of organisms to survive environmental stress (De Zwaan et al. 1995, Viarengo et al. 1995). $\mathrm{LT}_{50}$ values have been described to report significant information comparable with stress indices determined at the cellular level (Hellou \& Law 2003). The accuracy of air exposure as a monitoring tool has therefore been reported to reflect even finer differences among contaminated groups than other physiological measurements (Moles \& Hale 2003). The survival profiles for the populations under study are consistent with the gradient of pollution along the Galician coast. The locations Aguiño, Pindo and Lobeiras were identified as a homogeneous group in terms of greatest oil impact. Mussels from these locations presented the lowest performances in air together with Carrumeiro and compared to those individuals from Bueu, Miranda and Redes (Fig. 3). Lowest survival rates were noted in mussel seed from Carrumeiro, which also exhibited the higher PAH values. However, the low survival profile can also be interpreted according to specific abiotic factors other than fuel oil, which may play an additional role (i.e. salinity) and greatly influence performance in air. Clearly, mussel populations from the area with the greatest contaminant impact are less fit than those from locations far from the impact corroborating the usefulness of the survival parameter in this type of study.

\section{PAH contents}

The origin of PAHs in environmental samples can be assessed by its signature at molecular level. The ratios between parental and alkylated components as well as the relative abundance of 5-6 ring PAHs can be particularly useful for differentiating PAHs that originated at high temperatures (combustion), which are dominated by the parent species and from petrogenic sources (crude oils), which contain a wide range of alkyl-derivatives (Wang \& Fingas 2003).
The PAH composition found in seed mussels denotes a combination of fossil and pyrolytic sources. As shown in Fig. 4, the tissue extracts contained the whole set of 2- to 6-ring PAHs, currently considered as combustionderived, but the predominance of the methylphenanthrenes over the parent compound, and over the high molecular weight PAHs indicate a mixed petrogenic input. This source is more evident in the samples collected in the area most heavily impacted by the oil spill, namely from Aguiño to Lobeiras, reflecting the uptake of the oil hydrocarbons over a background load of pyrogenic PAHs, despite the time elapsed from the accident (November to December 2002) to seed gathering (February 2003).

The relative composition of these hydrocarbons in the mussel tissues and the corresponding grouping of samples are important in assessing the results of the biochemical indicators. For instance, the mussels from Bueu and Aguiño exhibited similar concentrations of total PAHs (Fig. 4), but the phenanthrene derivatives accounted for 20 and $40 \%$ of them consistently with the different degree of impact of the spill.

\section{Biochemical composition}

Our results are in agreement with the results obtained by Capuzzo \& Leavitt (1988) in Mytilus edulis collected along a contaminant gradient. The mussels subjected to higher levels of hydrocarbons were those with higher lipid content and a lipid/protein ratio with the only exception of mussels from Carrumeiro. This may be interpreted as an outlier derived from its exceptional location near a freshwater input (see 'Results: PAHs'). The hydrocarbon vs. lipid content relationship is reflected in seed grouping by impact areas or PAH content. The highest lipid contents in mussel seed were found in the Aguiño-Lobeiras and Pindo-Miranda groups, the areas most affected by the oil spill, as compared to less affected mussel populations, as well as our previous surveys with juveniles cultured on rafts under unpolluted conditions (Freites et al. 2003).

The composition of lipid class in the mussel seed from different origins showed a higher percentage of phospholipids in seed from the areas with a lower level of PAH persistence and/or oil spill impact. On the other hand, the increasing proportion of triglycerides to total lipids in zones with greater persistence and higher impact level was notably significant and higher than values obtained under unpolluted conditions of culture (Freites et al. 2002a). Three groupings were observed: the first (Aguiño, Lobeiras and Pindo) with percentage triglycerides (TG) greater than $25 \%$ of total lipids, the second (Carrumeiro and Miranda) with percentages 
between 6 and $12 \%$, and finally the zones furthest from the impact (Bueu and Redes) where TG presence was $0 \%$. The absence of TG in the mussels subject to less impact agrees with our previous results in mussel seed from an unpolluted, intertidal environment (Freites et al. 2002a).

With regard to sterols, the situation is the opposite with lower relative percentages in the seeds from zones of greater impact or persistency, and the highest values in zones furthest from the oil spill (Bueu and Redes). Values observed at Bueu and Redes were also similar to those obtained under unpolluted, cultured conditions (Freites et al. 2002a). The proportions of free fatty acids observed in the seeds of all origins were similar $(\sim 10 \%)$.

Among other effects, the rupture of the digestive epithelium is a general response to stress, resulting not only from exposure to a wide range of contaminants but also to extreme conditions (i.e. salinity and starvation). An increase in lipids within the cells is associated with this epithelial rupture, along with a narrowing of the lysosomes, an organule responsible for intracellular digestion. Working with Mytilus edulis collected along the contaminant gradient, Capuzzo \& Leavitt (1988) noted elevated TG content and TG/PH (phospholipid ratio. This suggests a decrease in TG mobilization to the $\mathrm{PH}$ pool with potential consequences on membrane structure and function. Similarly, Lowe (1988) observed changes in the characteristics of the digestive cell lysosomes in mussels exposed to PAHs in Langesundfjord (Norway). These studies showed that PAHs were sequestered in the lysosomes in cells with high lipid content. The accumulation of lipids is clearly associated with lysosomal dysfunction, and it may be considered to represent a form of degeneration of fats. These authors suggest that 'the mechanism of cytosolic lipid accumulation is presumably the result of a xenobiotic-induced imbalance between production and utilization', which may cleary be the case in our study for those populations more affected by the spill.

\section{Fatty acids}

The fatty acids of total lipids seem to suggest an alteration of certain biochemical processes involved in the synthesis of unsaturated (desaturases, especially $\Delta$ 9 unsaturated) and long chain acids (elongases etc). In an attempt to determine the existence of a relationship between both biosynthetic systems (insaturation and elongation), the saturated/monounsaturated ratio was compared with the 20:5n3/22:6n3 ratios. Fig. 6 suggests a strong negative linear relationship between both variables. Moreover, a significant geographical component can be observed in the distribution, which appears to be related to the magnitude of the oil spill on different points of the coast. Thus, samples from Aguiño showed the highest content of monounsaturated acids with the smallest elongation capacity of 20:5 to 22:6. The other sampling positions show intermediate values (Lobeiras and Pindo, saturated/monounsaturated ratio $<2$ ), whereas seeds from the sampling points least affected by the spill show normal saturated/monounsaturated ratios $(>2)$, together with high elongation capacities $(20: 5 \mathrm{n} 3 / 22: 6 \mathrm{n} 3$ ratio $<1)$.

Elevated levels of monounsaturated fatty acids could be related to the increase in activity of the mixed function oxygenase (MFO) system, the major phase I-type class of detoxification enzymes. These increases become obvious with exposure to xenobiotic agents (Petushok et al. 2002), and it should be remembered that these enzymes metabolize not only xenobiotics (hydrocarbons, pesticides, drugs) but a wide variety of substrates including endogenous molecules (fatty acids, eicosenoids, steroids) (Snyder 2000). This multi-enzymatic system contains different forms of cytochrome P450, cytochrome P450 reductase, and cytochrome $b_{5}$ and cytochrome $b_{5}$ reductase. Although hydroxylation has not yet been demonstrated as an intermediate step in double bond formation, the desaturation of fatty acids has all the characteristics of a mixed-function oxygenation (Gurr et al. 2002). The 3 components of animal $\Delta 9$-fatty acid desaturase complex are indeed NADH: cytochrome $b_{5}$ reductase, cytochrome $b_{5}$ and a cyanide sensitive desaturase component (Gurr et al. 2002). Our results seem to indicate that the increase in MFO activity induced by the presence of hydrocarbons could engender a concomitant increase in monounsaturase activity, thus affecting the normal profiles of fatty acid distributions in mussel. Although further research is necessary to confirm this, the saturated/monounsaturated fatty acid ratio could be, if this hypothesis is confirmed, a good indicator of mussel exposure to hydrocarbon contamination.

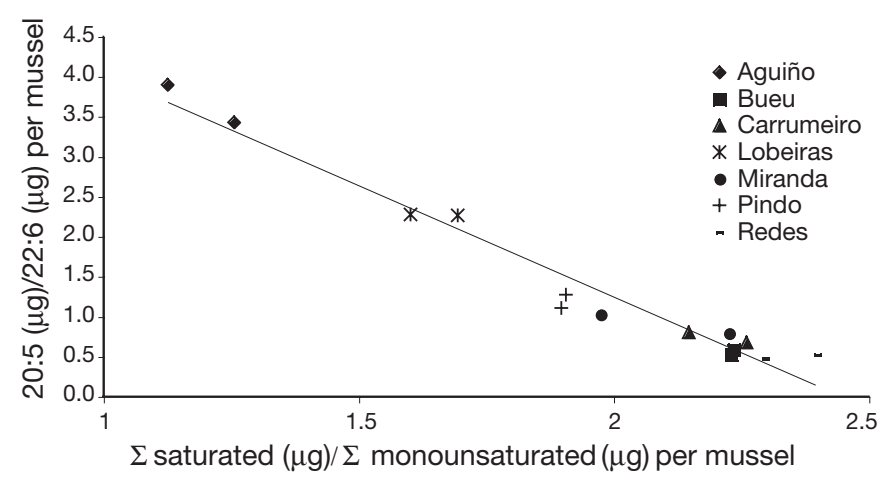

Fig. 6. Mytilus galloprovincialis. Ratio 20:5/22:6 vs. Esaturated/ इmonounsaturated fatty acids for the 7 mussel populations (2 samples per population) under study 


\section{CONCLUSIONS}

The results of the present survey allowed us to establish sub-lethal effects in wild mussel seed populations sampled 3 months after the 'Prestige' oil-spill, when the Autonomic Government Administration, Fisheries Department (Xunta de Galicia) had permitted collection of juveniles for its culture on rafts. These effects are observed in survival indices and alterations of lipid metabolism, especially in trygliceride and sterol fractions as well as saturated/monounsaturated fatty acid ratios.

The contents of PAHs in mussel seeds have allowed us to confirm the gradient of the oil spill impact on the different localities studied and its relationship with the proximity to the central area of the spill. Low values of PAHs in mussel seed reported in the present study might be explained by the particular characteristics of the 'Prestige' oil (see http://csciprestige.iim.csic.es/ informes/info01.pdf). PAH concentrations in adult wild mussels of the present spill (within the range 1 to $8 \mathrm{ug}$ $\mathrm{g}^{-1} \mathrm{DW}$ ) (see www.ieo.es/prestige/resultados.htm), are about $10^{4}$ times lower than those observed in the Aegen Sea oil spill, which occurred in the same geographical area in 1991. Nevertheless, cluster analysis and an individualised study of several PAHs have permitted us to establish a grouping and a gradient of the oil spill impact for the populations under study, despite the time elapsed between the accident (November to December 2002) and seed gathering (February 2003).

The present study showed the convenience of evaluating the oil spill impact using physiological and biochemical indicators in relation to other hydrocarbons, mostly those of the n-alkane series, that might also have an effect on metabolic routes of fatty acids and lipid matrix. PAHs have a similar effect, but they are not studied as much due to their non-cancerigenous character and higher biodegradation rate.

The effects observed in this study of wild mussel recruits exposed to the 'Prestige' oil spill will allow further analysison possible consequences on the growth, production and biochemical reserves cycle throughout the raft cultivation period and to evaluate the capacity of the individuals to repair alterations detected in the juvenile stage.

Acknowledgements. We thank B. González, L. Nieto, A. Ayala and M. Penabad for technical assistance. This study was supported by the contract-project PROINSA, Cultivos Marinos-Xunta de Galicia and the project MCYT VIM200320096-CO2-01

\section{LITERATURE CITED}

Alzaga R, Montuori P, Ortiz L, Bayona JM, Albaigés J (2004) Fast solid-phase extraction gas chromatography mass spectrometry procedure for oil fingerprinting. Application to the Prestige oil spill. J Chromatogr A 1025:133-138

Babarro JMF, Fernández-Reiríz MJ, Labarta U (2000a) Growth of seed mussel (Mytilus galloprovincialis): effects of the environmental parameters and seed origin. J Shellfish Res 19:187-193

Babarro JMF, Fernández-Reiríz MJ, Labarta U (2000b) Feeding behaviour of seed mussel Mytilus galloprovincialis: environmental parameters and seed origin. J Shellfish Res 19:195-201

Babarro JMF, Fernández-Reiríz MJ, Labarta U (2000c) Metabolism of the mussel (Mytilus galloprovincialis Lmk) seed: Oxygen consumption and excretion rate from two origins on cultivation raft. J Mar Biol Assoc UK 80(5): $865-872$

Babarro JMF, Fernández-Reiríz MJ, Labarta U (2003) In situ absorption efficiency processes for the cultured mussel (Mytilus galloprovincialis) in the Ria de Arousa. J Mar Biol Assoc UK 83:1059-1064

Bitman J, Wood DL (1982) An improved copper reagent for quantitative densitometric thin-layer chromatography of lipids. Chromatography 5(6):1155-1562

Bligh EG, Dyer WJ (1959). A rapid method of total lipid extraction and purification. Can J Biochem 37:911-915

Caldwell RS, Rosene BA, Calderone EM (1979) Fatty acid composition of phospholipids in thermally acclimating sculpins Leptocottus armatus treated with polychlorinated biphenyls Aroclor 1254. In: Vernberg FB, Calabrese A, Thurberg F, Vernberg FJ (eds) Marine pollution: functional responses. Academic Press, New York, p 271-290

Capuzzo JM (1996) The bioaccumulation and biological effects of lipophilic organic contaminants. In: Kennedy VS, Newell RIE, Eble AF (eds) The Eastern oyster Crassostrea virginica. Maryland Sea Grant College, MD, p 539-557

Capuzzo JM, Leavitt DF (1988) Lipid class composition of the digestive glands of Mytilus edulis and Carcinus maenas in response to contaminant gradients. Mar Ecol Prog Ser 46: 139-145

Capuzzo JM, Lancaster BA, Sasaki GC (1984) The effects of petroleum hydrocarbons on lipid metabolism and energetics of larval development and metamorphosis in the American lobster (Homarus americanus Milne Edwards). Mar Environ Res 14:201-228

Christie WW (1989) Gas chromatography and lipids: a practical guide. The Oily Press, Ayr

Darsie J, Gosha JK, Holman RT (1976) Induction of abnormal fatty acid metabolism and essential fatty acid deficiency in rats by dietary DDT. Arch Biochem Biophys 175:262-269

De Zwaan A, Cortesi P, Cattani O (1995) Resistance of bivalves to anoxia as a response to pollution-induced environmental stress. Sci Total Environ 171:121125

Farrington JW, Davis AC, Frew NM, Rabin KS (1982) No. 2 fuel oil compounds in Mytilus edulis. Retention and release after an oil spill. Mar Biol 66:15-26

Fernández-Reiriz MJ, Pérez-Camacho A, Ferreiro MJ, Blanco J, Planas M, Campos MJ, Labarta U (1989) Biomass production and variation in the biochemical profile (total protein, carbohydrates, RNA, lipids and fatty acids) of seven species of marine microalgae. Aquaculture 83: $17-37$

Freeman CP, West D (1966) Complete separation of lipid classes on a single thin-layer plate. J Lipid Res 7:324-327

Freeman KR (1974) Growth, mortality and seasonal cycle of Mytilus edulis in two Nova Scotian embayments. Department of the Environment, Fisheries and Marine Service, Canada, Technical Report No. 500, p. 112

Freites L, Fernández-Reiríz MJ, Labarta U (2002a) Lipid 
classes of mussel seeds Mytilus galloprovincialis of subtidal and rocky shore origin. Aquaculture 207:97-111

Freites L, Fernández-Reiriz MJ, Labarta U (2002b) Fatty acid profiles of Mytilus galloprovincialis mussel seeds of subtidal and rocky shore origin. A comparative study. Comp Biochem Physiol Part B 132(2):453-461

Freites L, Fernández-Reiriz MJ, Labarta U (2002c) Evolution of fatty acid profiles of Mytilus galloprovincialis mussels seeds (subtidal and rocky shore origins). Influence of environmental parameters. J Exp Mar Biol Ecol 268 (2): 185-204

Freites L, Fernández-Reiriz MJ, Labarta U (2003) Energy content and biochemical substrates of subtidal and rocky shore mussel seed (Mytilus galloprovincialis) in Galician raft culture. Cienc Mar 29(4B):603-619

Garrido JL, Medina I (1994) One-step conversion of fatty acids into their 2-alkenyl-4,4-dimethyloxazoline derivatives directly from total lipids. J Chromatogr A 673: 101-105

Garrido JL, Medina I (2002) Identification of minor fatty acids in mussels (Mytilus galloprovincialis) by GC-MS of their 2alkenyl-4,4-dimethyloxazoline derivatives. Anal Chim Acta 465:409-416

Gurr MI, Harwood JL, Frayn KN (2002) Lipid biochemistry. An introduction, 5th edn. Blackwell Science, Oxford

Hamilton MA, Russo RC, Thurston RV (1997) Trimmed Spearmen-Karber method for estimating median lethal concentrations in toxicity bioassays. Environ Sci Technol 11: 714-719

Hellou J, Law RJ (2003) Stress on stress response of wild mussels, Mytilus edulis and Mytilus trossulus, as an indicator of ecosystem health. Environ Pollut 126:407-416

Kaplan EL, Meier P (1958) Nonparametric estimation from incomplete observation. J Am Stat Assoc 53:457-481

Kato N, Kawai K, Yoshida A (1982) Effects of dietary polychlorinated biphenyls and protein level on liver and serum lipid metabolism of rats. Agric Biol Chem 46:703-708

Larretxea X, Pérez-Camacho A (1996) Evolución temporal de la contaminación por hidrocarburos en el mejillón de batea. Incidencia de concentraciones subletales de la fracción acomodada en agua sobre los parámetros del balance energético. In: Vicent JR(ed) Seguimiento de la contami-

Editorial responsibility: Charles Peterson (Contributing Editor), Morehead City, North Carolina, USA nación producida por el buque AEGEN SEA. Ministerio de Medio Ambiente, Madrid

Lowe DM (1988) Alterations in cellular structure of Mytilus edulis resulting from exposure to environmental contaminants under field and experimental conditions. Mar Ecol Prog Ser 46:91-100

Lowry OH, Rosebrough NJ, Fair AL (1951) Protein measurement with the folin phenol reagent. J Biol Chem 193: 265-275

Medina I, Linares F, Garrido JL (1994) Use of a packed programmed-temperature vaporizer injector in the solvent elimination mode for the determination of fatty acid methyl esters by gas chromatography. J Chromatogr A 659:472-476

Moles A, Hale N (2003) Use of physiological responses in Mytilus trossulus as integrative bioindicators of sewage pollution. Mar Pollut Bull 46:954-958

Petushok N, Gabryelak T, Palecz D, Zavodnik L, SzollosiVarga I, Déer KA (2002) Comparative study of the xenobiotic metabolising system in the digestive gland of the bivalve molluscs in different aquatic ecosystems and in aquaria experiments. Aquat Toxicol 61:65-72

Porte C, Biosca X, Pastor D, Solé M, Albaigés J (2000) The Aegean Sea oil spill. 2. Temporal study of the hydrocarbons accumulation in bivalves. Environ Sci Technol 34: 5067-5075

Snyder MJ (2000) Cytochrome P450 enzymes in aquatic invertebrates: recent advances and future directions. Aquat Toxicol 48:529-547

Strickland JD, Parsons TR (1968) A practical handbook of seawater analysis. Bull Fish Res Board Can 167: 311

Thomas RE, Harris PM, Rice SD (1999) Survival in air of Mytilus trossulus following long-term exposure to spilled Exxon Valdez crude oil in Prince William sound. Comp Biochem Physiol C 122:147-152

Viarengo A, Canesi L, Pertica M, Mancinelli G, Accomando R, Smaal AC, Orunese M (1995) Stress on stress response: a simple monitoring tool in the assessement of general stress syndrome in mussels. Mar Environ Res 39:245-248

Wang Z, Fingas MF (2003) Development of oil hydrocarbon fingerprinting and identification techniques. Mar Pollut Bull 47:423-452

Submitted: December 27, 2004; Accepted: June 9, 2005 Proofs received from author(s): October 13, 2005 